\title{
Efeito da estrutura ovárica e da idade de bovinos da raça Holstein Friesian na quantidade e qualidade de ovócitos e de embriões produzidos in vitro
}

\author{
A. REIS 1 \\ R. METELO ${ }^{1}$ \\ P. SANTOS ${ }^{1}$ \\ F. Moreira da SILVA ${ }^{1}$
}

\section{Correspondência para:}

F.MOREIRA DA SILVA

Universidade dos Açores - DCA

Largo da Igreja, Terra-Chã - 9700

Angra do Heroísmo - Portugal

jsilva@notes.angra.uac.pt

Recebido para publicação: 07/10/2004 Aprovado para publicação: 23/08/2005

\author{
1 - Departamento de Ciências Agrárias da Universidade dos Açores, Angra \\ do Heroismo - Portugal
}

\section{Resumo}

O objetivo do presente trabalho, foi o estudo dos efeitos da idade e da fase do ciclo estral dos bovinos na quantidade e qualidade de ovócitos e de embriões produzidos in vitro. Para isso, foram utilizados ovócitos de 63 vacas da raça Holstein-Friesian abatidas em matadouro, com idades compreendidas entre 1 e 15 anos, as quais foram divididas em 5 lotes de acordo com a idade. Cada lote foi subdividido de acordo com a fase do ciclo estral em que o animal se encontrava no dia do abate, pela presença ou não de corpo lúteo funcional na superfície do ovário. Os lotes referentes à idade foram: $<2$; $[2,4] ;[5,6] ;[7,8]$ e $>8$ anos. Após punção dos folículos, os ovócitos foram divididos nas classes A, B, C e D, tendo em conta o seu aspecto morfológico, em que apenas os de classe A e B foram usados para a FIV. Observou-se que o número de ovócitos produzidos foi diretamente proporcional à idade das vacas $(\mathrm{R}=0,99$ - $\mathrm{P}<0,001)$. Quanto à fase do ciclo estral, as vacas em fase luteínica, produziram maior número de ovócitos que as vacas em fase folicular $(\mathrm{P}<0,001)$, respetivamente 7,05 $\pm 0,11$ e 10,87 $\pm 1,01$. Relativamente à qualidade dos ovócitos em função da idade das vacas, observou-se uma correlação positiva $(R=0,94 \mathrm{p}<0,01)$ até aos $[7,8]$ anos, começando a baixar a partir desta idade. As vacas em fase luteínica produziram ovócitos de melhor qualidade relativamente às vacas em fase folicular $(6,77 \pm 0,64$ e 3,84 0 0,64; respetivamente). Quanto à quantidade de zigotos que clivaram, esta foi superior para os lotes de vacas em fase luteínica em comparação com os de vacas em fase folicular (59,03\% e 45,52\%; respetivamente), observando-se ainda que as vacas em fase luteínica produziram igualmente, em geral, maior número de embriões aos 7 dias após FIV que as vacas em fase folicular(44,23\% e 31,48\%; respetivamente). Os resultados do presente trabalho permitem concluir que existe uma estreita relação entre a idade e a fase do ciclo estral das vacas e a quantidade e qualidade dos ovócitos e de embriões produzidos in vitro.

\section{Introdução}

A produção in vitro de embriões de bovino, surgiu como uma arma útil não só para estudos de investigação científica, como também para aplicações comerciais. Durante os anos 90 as técnicas de cultura in vitro tornaram-se largamente utilizadas em muitos países. Estes embriões produzidos in vitro vêm também satisfazer as exigências da biotecnologia, para a produção de animais

\author{
Palavras-chave: \\ Fecundação in vitro. \\ Folículo. \\ Maturação in vitro. \\ Ovário. \\ Produção de embriões in vitro.
}

transgênicos e clones. Contudo, de Wit , Wurth e Kruip ${ }^{1}$ descreveram que a produção in vitro de embriões é muito ineficiente comparada com a produção in vivo: apenas 20 a 30\% dos complexos cumulus-ovócito (COC's) conseguem chegar ao estado de blastocisto após a produção in vitro de embriões, sendo a maturação dos ovócitos o passo mais crítico na produção de embriões. Outros autores, de Wit e Kruip ${ }^{2}$ mencionam que o tamanho dos folículos 
influencia o potencial de desenvolvimento dos ovócitos, assim como o seu próprio diâmetro. Marques ${ }^{3}$ acrescenta ainda, que as condições de transporte dos ovários e as inadequadas condições de cultura após a seleção, podem ser outras das causas de tão baixo rendimento. Apesar de tão baixo rendimento, a produção in vitro de embriões bovinos a partir de ovócitos imaturos oferece uma alternativa comercial viável aos programas baseados em ovulações múltiplas e técnicas de transferência de embriões para o melhoramento genético dos animais. Esta técnica fornece um grande número de ovócitos e de embriões em estadios prédefinidos disponíveis para estudos sobre a pré-implantação e desenvolvimento dos bovinos, apesar de no máximo $40 \%$ ser o limite de blastocistos produzidos ${ }^{2,4}$.

A produção in vitro de embriões compreende três fases consecutivas, nomeadamente a maturação dos ovócitos, a sua fecundação e por fim a cultura dos embriões.

A quantidade de ovócitos susceptíveis de produzir embriões in vitro depende tanto de fatores extrínsecos, e.g. condições ambientais e manipulação a que estes são sujeitos, assim como do próprio ovário e do estoque de folículos que este possui. Este estoque, com uma média de 50000 a 100 000 folículos primordiais existentes ao nascimento, vai aumentando com a idade, começando a diminuir por volta dos 9 anos de idade ${ }^{5}$.

Os ovócitos de doadoras com um mês de idade são apropriados para a FIV, mas produzem um número significativamente mais baixo de blastocistos comparado com os ovócitos de doadoras adultas ${ }^{6,7}$.

Os ovócitos provenientes de folículos com tamanho superior a $6 \mathrm{~mm}$, têm muito mais capacidade de se desenvolverem em embriões transferíveis depois da fecundação, do que os ovócitos oriundos de pequenos folículos ${ }^{8,9,10}$.

O objectivo primordial do presente trabalho foi o estudo dos efeitos da idade e da fase do ciclo sexual dos bovinos na quantidade e qualidade de ovócitos e de embriões produzidos após fecundação in vitro.

\section{Materiais e Métodos}

Foram utilizados ovários recolhidos no matadouro da Ilha Terceira - Açores de um total de 63 vacas da raça HolsteinFriesian, com idades compreendidas entre 1 e 15 anos, as quais foram divididas em 5 lotes de acordo com a idade, tendo cada lote sido subdividido de acordo com a fase do ciclo estral em que o animal se encontrava no dia do abate. Os lotes referentes à idade foram: <2; [2,4]; [5,6]; [7, 8] e $\geq 8$ anos. A fase do ciclo estral foi avaliada pela presença ou ausência de corpo lúteo funcional na superfície do ovário, tendo os animais sido divididos em dois grupos - fase luteínica e fase folicular.

\section{Colheita dos ovários e ovócitos}

Os ovários foram transportados ao laboratório, em frascos individuais, numa solução salina fisiológica com antibiótico e a $30-37^{\circ} \mathrm{C}$. Os ovários com folículos antrais, dos quais seriam retiradas as células da granulosa foram transportados a $4^{\circ} \mathrm{C}$. À chegada ao laboratório, os ovários foram lavados três vezes na solução salina restante, previamente aquecida em Banho-Maria a $39^{\circ} \mathrm{C}$, sendo o líquido folicular aspirado com ajuda de agulha $19 \mathrm{G} \times 1 \frac{1}{2}$ TWB (TERUMO 19x1" - 1.1-25mm) e seringa (GLISS, 5ml, ref, NN-1925). Para cada vaca os folículos visíveis na superfície dos ovários, com tamanhos compreendidos entre $4-10 \mathrm{~mm}$ foram aspirados para um tubo Falcon de $15 \mathrm{ml}$. Os folículos de cor escura e císticos não foram aspirados. Entre a coleta dos ovários e a aspiração do líquido folicular, não decorreram mais que duas horas.

\section{Triagem e lavagem dos ovócitos}

Após aspiração, os ovócitos foram imediatamente colocados em meio de lavagem W1 à base de TCM 199. A hora 
em que se procedeu à colocação dos ovócitos em meio de lavagem foi considerada a hora zero, uma vez que nos serviu de referência para todas as outras manipulações.

Após lavagem dos ovócitos em três banhos consecutivos, este foram contabilizados e divididos pelas categorias: A, B, C e D de acordo com a classificação de Wurth et al. ${ }^{12}$ em que:

COC A - ovócito com cumulus brilhante e expandido;

COC B - ovócito com cumulus expandido, mas com menos células e mais escuras que $\mathrm{O}$ anterior;

COC C - ovócito com cumulus exageradamente expandido com células degeneradas, formando aglomerados mais escuros;

COC D - ovócito desnudado, com zona pelúcida exposta.

Em cada um dos primeiros 3 banhos, os ovócitos de categoria $\mathrm{C}$ e $\mathrm{D}$ foram excluídos, sendo apenas utilizados para maturação os ovócitos de classe A e B.

\section{Maturação in vitro}

A maturação foi efetuada em placas de cultura de 4 poços (Nunc, ref.:176740), contendo $100 \mathrm{ml}$ de meio de maturação constituído por meio TCM 199 suplementado com $10 \%$ de soro de vaca superovulada (SOCS) e com antibiótico (Penicilina-Streptomicina: $20 \mathrm{ml} / \mathrm{ml})^{13}$. Estas gotas foram cobertas com óleo mineral. As placas de cultura foram imediatamente colocadas em estufa com ambiente controlado a $39^{\circ} \mathrm{C}, 5 \% \mathrm{CO}_{2}$ em ar e $100 \%$ de umidade relativa do ar, onde esteve a maturar durante $24 \mathrm{~h} \pm 0,5$.

\section{Fecundação in vitro}

O sêmen foi descongelado mergulhandose a palheta de $0,25 \mathrm{ml}$ contendo $20 \times 10^{6} \mathrm{spz}$ em banho-maria aproximadamente 10 segundos a $37^{\circ} \mathrm{C}$. O conteúdo da palheta foi então colocado sobre um gradiente de Percoll (3ml de Percoll 45\% - 0,50805 g/ml colocado sobre $3 \mathrm{ml}$ de Percoll 90\% - 1,0161 $\mathrm{g} / \mathrm{ml})$. O conjunto foi então levado a centrifugar durante $20 \mathrm{~min}$ a $1000 \mathrm{~g}$ com vista à eliminação do crioprotetor e à separação dos espermatozóides viáveis dos não viáveis.

Os ovócitos foram lavados 3x em $\mathrm{H}$ TALP e 1x em IVF-TALP. Retirou-se o sobrenadante do sêmen centrifugado, onde se encontravam os espermatozóides mortos e os não viáveis, deixando aproximadamente $2 \mathrm{ml}$ no tubo juntamente com a pellet, onde se encontravam os espermatozóides viáveis e juntou-se o meio SP-TALP, voltando a centrifugar durante $20 \mathrm{~min}$ a $1000 \mathrm{~g}$ de modo a eliminar os vestígios de Percoll.

As placas de Petri foram preparadas com gotas de 40ul de meio IVF-TALP e cobertas com óleo mineral.

Retirou-se o sobrenadante ao meio posto a centrifugar deixando $\pm 2 \mathrm{ml}$ e faz-se uma última centrifugação de apenas $5 \mathrm{~min}$ a $1000 \mathrm{~g}$ com o meio IVF-TALP restante. O sobrenadante, foi de novo retirado, deixando $\pm 150 \mu$ l. Juntou-se então a cada poço uma quantidade de $10^{6} \mathrm{spz} / \mathrm{ml}$, indo a fecundar durante 18 a 24 horas em estufa com atmosfera controlada a $39^{\circ} \mathrm{C}, 5 \% \mathrm{CO}_{2}$ em ar e $100 \%$ de umidade relativa do ar.

\section{Desenvolvimento dos embriões}

Após 18 a 24 horas, os possíveis zigotos foram lavados num meio de cultura de embriões à base de TCM 199 suplementado com $10 \%$ de soro de vaca superovulada (SOCS) e com antibiótico (Penicilina-Streptomicina: $20 \mathrm{ml} / \mathrm{ml}$ ).

Com ajuda de 2 agulhas de insulina, foram retiradas as células do cumulus-ophorus existentes à volta do "zigoto". Os "zigotos" foram então colocados na co-cultura de células da granulosa, previamente preparada de acordo com Silva e Metelo ${ }^{13}$.

Ao $3^{\circ}, 5^{\circ}$, e $7^{\circ}$, dias foi observada a evolução dos embriões, tendo sido avaliado o seu estado de desenvolvimento recorrendo a critérios morfológicos. No quinto dia, apenas foram contabilizados os embriões no estadio de desenvolvimento superior ou igual a mórula e, no sétimo dia a partir de mórula compacta. 
Tabela 1 - Média de COC's produzidos por vaca consoante a fase do ciclo estral. Os valores representam a média \pm o desvio padrão

\begin{tabular}{ccc}
\hline Fase do ciclo estral & $\begin{array}{c}\text { Média de COC's colhidos por } \\
\text { vaca }\end{array}$ & $\begin{array}{c}\text { Média de COC's A e B } \\
\text { colhidos por vaca }\end{array}$ \\
\hline Folicular & $7,05 \pm 0,91$ & $3,84 \pm 0,64$ \\
Luteínica & $10,87 \pm 1,01$ & $6,77 \pm 0,64$ \\
\hline & $\mathrm{P}<0,001$ & $\mathrm{P}<0,001$ \\
\hline
\end{tabular}

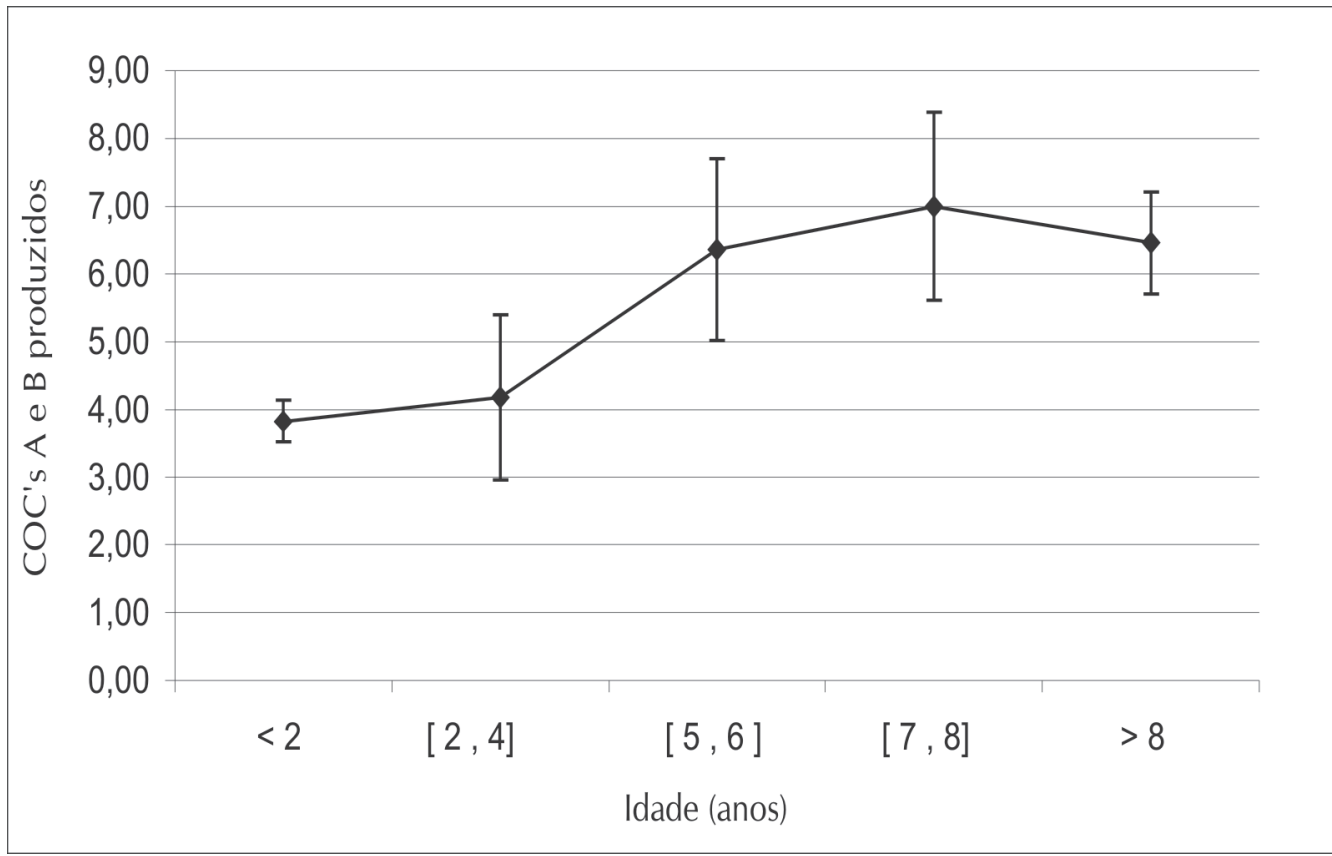

Figura 1 - Média de COC's A e B produzidos consoante a idade da vaca. Os valores representam a média \pm desvio padrão de 63 vacas

\section{Resultados e Discussão}

Quanto ao número total de ovócitos, observou-se que este foi diretamente proporcional $(\mathrm{R}=0,99 ; \mathrm{P}$ $<0,001)$ à idade das vacas, variando de $6,00 \pm 1,00$ para vacas com idade inferior a 2 anos, a $11,55 \pm 1,52$ para vacas com idades superiores a 8 anos. Para os outros grupos etários dos animais, observou-se que para as vacas com idades entre 2-4; 5-6 e 7-8 anos, o número total de ovócitos produzidos foi respectivamente de $7,73 \pm 1,75 ; 9,50$, $\pm 1,76$ e $10,54 \pm 1,72$. Este fato poderá ser explicado tendo em conta a relação existente entre a idade das vacas e o tamanho dos ovários. Thibier ${ }^{14}$ descreveu existir uma relação direta entre o tamanho dos ovários e a idade dos animais. Os ovários das vacas com mais de 8 anos, chegam aos $5 \mathrm{~cm}$ de comprimento, sendo desta forma capazes de suportar um maior número de folículos na sua superfície que os ovários das vacas com idade inferior a 2 anos que têm tamanho aproximado de $1,5-2 \mathrm{~cm}$.

Dividindo as vacas de acordo com o ciclo estral, observamos existir diferença significativa $(\mathrm{P} £ 0,001)$ no número de ovócitos obtidos entre as vacas em fase folicular e as vacas em fase luteínica. As vacas em fase luteínica produziram, em média, $10,87 \pm 1,01$, enquanto que as vacas em fase folicular produziram, em média, 7,05 \pm 0,91 ovócitos (Tabela 1). Foi também 


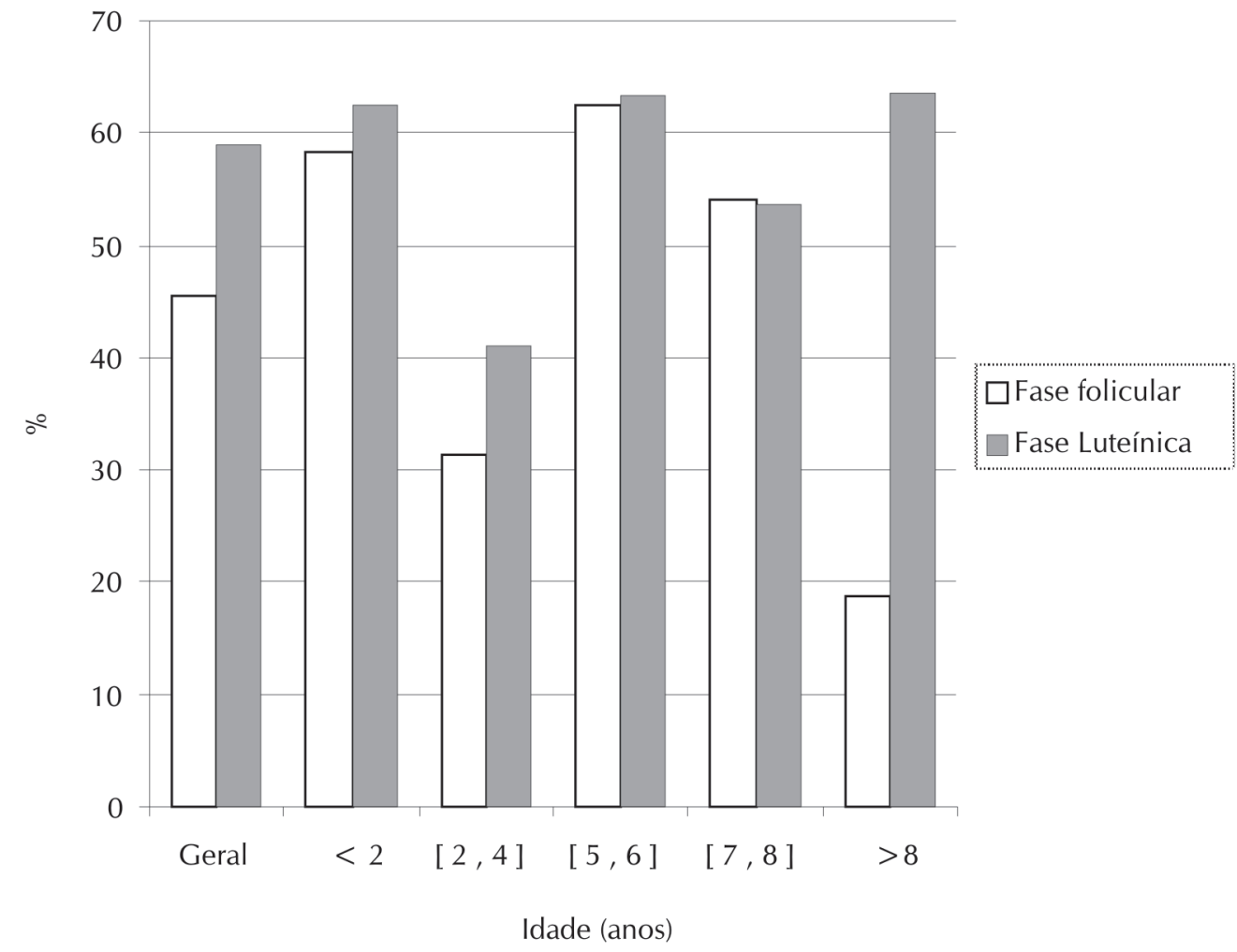

Figura 2 - Comparação da taxa de clivagem dos COC's das vacas em função da fase estral

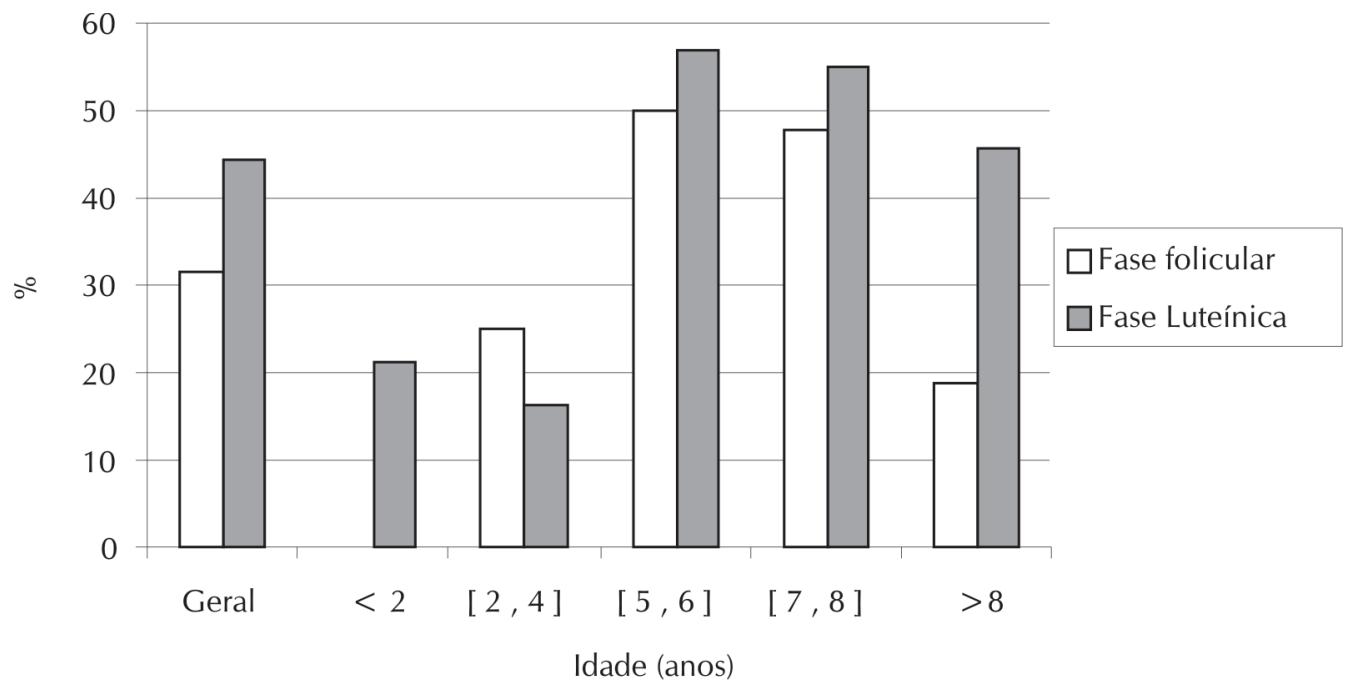

Figura 3 - Comparação da produção de embriões sete dias após FIV em função da idade e fase do ciclo estral 
demonstrado no presente trabalho que existe uma diferença significativa $(\mathrm{P}<0,001)$ entre a qualidade dos COC's produzidos por vacas em fase luteínica relativamente à qualidade dos COC'S das vacas em fase folicular. As vacas em fase luteínica produziram uma média de 6,77 \pm 0,64 COC's de qualidade $A+B$, enquanto que as vacas em fase folicular, apenas produziram cerca de metade deste valor $3,84 \pm 0,64$ (Tabela 1). Verificou-se ainda haver uma relação direta $(\mathrm{R}=0.94-\mathrm{P}<0,01)$ entre a qualidade dos COC's e a idade das vacas até aos 8 anos de idade, após o qual decresce (Figura 1).

Hasler ${ }^{15}$ defende que a resposta ovárica (produção de ovócitos) varia em função da idade, atingindo-se um pico por volta dos 9 anos de idade, voltando depois a decrescer. Conjuntamente a essa resposta ovárica, este autor defende existir ainda a mesma relação para o número de embriões produzidos, a qual varia na mesma proporção.

Quanto à taxa de clivagem, quando foi considerada a fase do ciclo estral, observou-se que os COC's provenientes de vacas em fase luteínica apresentaram uma taxa de clivagem superior aos provenientes de vacas em fase folicular em mais de 15,5\% como se pode observar na figura 2 , à excepção do grupo com idades compreendidas entre [7, 8] anos. Para estes animais, as taxas de clivagem foram aproximadamente iguais para a fase folicular $(54,17 \%)$ e fase luteínica $(53,71 \%)$. Da mesma forma, e de uma maneira geral, os COC's das vacas em fase folicular produziram um menor número de embriões que os COC's das vacas em fase luteínica ( $\mathrm{P}<0,001$ (Figura 3).

O fato das vacas que estavam em fase luteínica do ciclo estral, terem uma maior taxa de fecundação e de desenvolvimento dos seus embriões pode dever-se aos ovários possuírem um maior número de folículos pertencentes a várias ondas foliculares, os quais não sofreram ainda um processo tão acentuado de atrésia, como acontece quando na superfície do ovário temos um folículo muito desenvolvido que vai ovular no final da fase folicular. Desta forma, quando sujeitos a $24 \mathrm{~h} \pm 0,5$ de maturação in vitro $\mathrm{e}$ posteriormente fecundados, o resultado dos ovócitos das vacas em fase luteínica é superior ao das vacas em fase folicular. Sabe-se contudo que os ovócitos pertencentes a folículos médios e grandes mostram maior potencial de desenvolvimento, apresentando por isso maior apetência para serem fecundados de acordo com Pavlok, Lucas Hahn e Niemann ${ }^{16}$; Blondin e Sirard, (1995) e com Tan e Lu ${ }^{11}$. Arloto et al. ${ }^{18}$, defendem que o tamanho do folículo está relacionado com o tamanho do ovócito, o qual está ainda diretamente relacionado com o seu potencial de desenvolvimento ${ }^{1}$.

As vacas com maior produção de ovócitos A e B bem como uma maior taxa de embriões, foram as vacas que estavam em fase luteínica, com idades compreendidas entre - $[5,6]$ e $[7,8]$. Estes dados estão de acordo com de Wit e Kruip ${ }^{2}$, que afirmam haver uma relação positiva entre a qualidade dos COC's e a qualidade/quantidade dos embriões produzidos.

Quanto à relação entre taxa de clivagem e número de embriões produzidos, observamos que apesar das vacas de idade inferior a 2 anos terem taxas de clivagem relativamente elevadas quando comparadas com as das outras faixas etárias, quer se encontrassem na fase folicular (58,34\%) quer em fase luteínica $(62,50 \%)$, a sua produção de embriões desceu para valores basais, sendo, inclusivamente nula no grupo de animais que se encontrava em fase folicular. Isto está de acordo com Leveske e Sirard ${ }^{6}$ e com Revel et al. ${ }^{7}$, que afirmam que os COC's de doadoras com menos de um ano de idade apesar de serem apropriados para a FIV, produzem um número relativamente baixo de embriões viáveis. $\mathrm{O}$ presente trabalho permite-nos inferir que o número de COC's produzidos é diretamente proporcional à idade das vacas, havendo ainda uma relação entre o estado ovárico e a quantidade de ovócitos produzidos: as 
vacas em fase luetínica produzem um maior número total de COC's do que as vacas em fase folicular. Quanto à qualidade, existe um aumento de produção de COC's de qualidade A e B, desde as vacas com idade inferior a 2 anos até vacas com idade compreendida de 7 a 8 anos, baixando a partir deste idade. Além da idade, as vacas em fase luteínica produzem uma melhor qualidade de COC's do que as vacas em fase folicular. Quanto à produção de embriões, verifica-se uma maior taxa de clivagem dos zigotos das vacas em fase luteínica em comparação com as vacas em fase folicular, independentemente da idade das vacas/ novilhas, tendência esta que se mantém relativamente à produção geral (incluindo todas as idades) de embriões. Para as novilhas com idade inferior a 2 anos e vacas com idades superior a 8 anos, apesar das taxas de clivagem serem relativamente elevadas, a produção de embriões in vitro destas vacas desce para valores basais.

Por tudo isto se conclui que há uma relação estreita entre a idade e a fase do ciclo estral das vacas na quantidade e qualidade dos COC's bem como da posterior produção in vitro de embriões.

\section{Agradecimentos}

Este trabalho foi financiado pela Fundação Luso-Americana para o Desenvolvimento, Projecto no 379/03.

\section{Effect of ovarian structure and bovine's age on amount and quality of oocytes and in vitro embryo production}

\section{Abstract}

The aim of the present study was the evaluation of whether the age or the estrous cycle phase would influence the quantity and/or quality of oocytes and in vitro embryo production. Oocytes from ovaries of 63 Holstein- Friesian slaughtered cows, aging between 1 and 15 years old, were divided into 5 groups considering their age and then subdivided according to their phase of estrous cycle. The groups were: $<2 ;[2,4] ;[5,6] ;[7,8]$ and $>8$ years old. The estrous cycle phase (lutheal or follicular) was evaluated by the presence or absence of a functional corpus luteum. The cumulus-oocyte-complex (COC's) was divided in classes A, B, C and D according to their morphological aspect. The COC's classed as $C$ and $\mathrm{D}$ were excluded, being the COC's classed as A and B matured in vitro and fertilized. As result of the study, it was observed that the number of total produced COC's was directly proportional to the age of the cow $(R=0,99-\mathrm{P}<0,001)$. It has also noticed that cows in the lutheal phase produced more COC's than cows in the follicular phase $(\mathrm{P}<0,001)$, respectively $7,05 \pm 0,11$ and $10,87 \pm 1,01$. The COC's quality augmented from the group of cows aging less than 2 years to cows aging between $[7,8]$ years old, with a positive correlation $(\mathrm{R}=0.94 \mathrm{p}<0.01)$ starting then to decrease. It was also realized that cows in the lutheal phase produced better COC's quality than cows in the follicular phase $(6,77 \pm 0,64$ e 3,84 \pm 0,64 ; respectively). In what cleavage rate is concerned, better results were achieve with cows in lutheal phase $(59,03 \%)$ then in follicular phase $(45,52 \%)$. It was also possible to notice a better embryo production in cows in the lutheal phase $(44,23 \%)$ then cows in the follicular phase. The results of the present study allow to conclude that there is a relation between the age and the estrous cycle stage in the quality and quantity of COC's and in vitro produced bovine embryos.

\section{Key-words:}

In vitro embryo production. In vitro fertilization. In vitro maturation. Follicle.

Ovary. 


\section{Referências}

1 WIT, A. A. C.; WURTH, Y. A.; KRUIP, T. A. M. Effect of ovarian phase and follicle quality on morphology and development capacity of the bovine cumulusoocyte-complex. Journal of Animal Science, v. 78, p. 1277-1283, 2000.

2 WIT, A. A. C.; KRUIP, T. A. M. Bovine cumulusoocyte-complex quality is reflected in sensitivity for áamanitin, oocyte-diameter and development capacity. Animal Reproduction Science, v. 65, p. 51-65, 2001.

3 MARQUES, C. M. F. C. V. Contribuição ao estudo da maturação de oócitos e cultura de embriões bovinos in vitro. 1998. Dissertação (Assistente de Investigação), Instituto Nacional de Investigação Agrária - Estação Zootécnica Nacional, 1998.

4 NIEMANN, H.; WRENZYCKI, C. Alterations of expression of developmentally important genes in preimplantation bovine embryos by in vitro culture conditions: implications for subsequent development. Theriogenology, v. 53, p. 21-34, 1999.

5 MOREIRA DA SILVA, J.F. Superovulation chez les bovins, 1990. 103 p. Tese - Departamento de Ciências Agrárias. Universidade dos Açores, Angra do Heroísmo - Portugal.

6 LEVESQUE, J. T.; SIRARD, M. A. Proteins in oocytes from calves and adult cows before maturation: relationship with their development capacity. Reproduction - Nutrition - Development, v. 34, p. 133-139, 1994.

7 REVEL, F.; ET AL. Low developmental capacity of in vitro matured and fertilized oocytes from calves. Journal of Reproduction and Fertility, v. 103, p. 115-120, 1995.

8 BARNES, F.; ET AL. Embryo cloning in cattle: the use of in vitro matured oocytes. Journal of Reproduction and Fertility v. 97, p. 317-320, 1993.

9 LONERGAN, P.; ET AL. Effect of follicle size on bovine oocyte quality and developmental competence following maturation, fertilization and culture in vitro. Molecular Reproduction and Development, v. 37, p. 48-53, 1994.

10 STAIGMILLER, R. B. In vitro methods for production of viable oocytes. Journal of Animal Science, v. 66, p. 54-64, 1998.

11 BLODIN, P.; SIRARD, M. A. Oocyte and follicular morphology as determining characteristics for developmental competence in bovine oocytes. Molecular Reproduction and Development, v. 41, p. 54-62, 1995.

12 WURTH, Y. A.; ET AL. Bovine embryo production in vitro after selection of ovaries, follicles and oocytes. In: INTERNATIONAL CONGRESS OF ANIMAL
PRODUCTION, 12., 1992, The Netherlands. [ Proceedings .... The Hague, 1992, p. 387-389.

13 SILVA, J. M.; METELO, R. Physical properties of the zona pellucida and viability of bovine embryos after slow freezing and vitrification. Reproduction in Domestic Animals; v. 40, n. 3, p. 205-209, 2005.

14 THIBIER, M. Les prostaglandines. Economie et Médicine Animales, v. 17, n. 13, 1976.

15 HASLER, J. F.; BROKE, G. P.; GAULEY, A. D. The relationship between age and response to super ovulation in Holstein cows ad heifers. Theriogenology, v. 15, p. 109, 1981.

16 PAVLOK, A.; LUCAS-HAHN, A.; NIEMANN, H. Fertilization and development competence of bovine oocytes derived from different categories of antral follicles. Molecular Reproduction and Development, v. 31, p. 63-67, 1992.

17 TAN, S. J.; LU, K. H. Effects of different oestrous stages of ovaries and sizes of follicles on generation of bovine embryos in vitro. Theriogenology, v. 38, p. 905919, 1990.

18 ARLOTTO, T.; ET AL. Aspects of follicle and oocyte stage that affect in vitro aturation and development of ovine oocytes. Theriogenology, v. 45, p. 943-956, 1996. 